\title{
Study Of Hematological Profile In Rheumatoid Arthritis Patients
}

\author{
Dr.R.Arul ${ }^{1}$, Dr.P.Praveen Kumar ${ }^{2}$ \\ ${ }^{1}$ Assistant professor in Nephrology, Coimbatore Medical college hospital, Coimbatore. \\ ${ }^{2} J u n i o r$ Resident in General Medicine, Coimbatore Medical college hospital, Coimbatore.
}

\begin{abstract}
Introduction

Of the systemic lesions caused by rheumatoid arthritis, anemia and a focal subcutaneous granuloma are the most characteristic. Our aim is to study the hematological status in patients with rheumatoid arthritis and to find out the prevalence of anemia in these patients and its correlation with seropositivity and disease activity which is measured by DAS 28 score(Disease activity score).

Methods: It is a cross-sectional prospective study using convenient simple random sampling of 44 patients attending the rheumatology clinic in Coimbatore medical college hospital over a period of one year.

Results: Sex ratio of females to males is this study is 4:1. The risk of developing disease is greatest between 40 to 49 years. Rheumatoid factor positivity is $80 \%$ and rheumatoid factor negativity is $20 \%$. The prevalence of anemia in rheumatoid arthritis patients is $75 \%$. In rheumatoid factor positive patients mean Hb values is less $(9.11 \mathrm{gm} \%)$ compared to rheumatoid factor negative patients $(10.23 \mathrm{gm} \%)$. Iron deficiency anemia patients mean $\mathrm{Hb}$ is lower (8.6gm\%) than in anemia of chronic disease is $(10.9 \mathrm{gm} \%)$. The prevalence of rheumatoid arthritis according to DAS 28 score categories in decreasing order are moderate $52.3 \%$, severe $45.5 \%$ and mild 4.5\%. Anemia is very well correlated with rheumatoid factor positivity, disease activity (DAS 28 score) ,duration of disease and ESR. Microcytic hypochromic anemia (iron deficiency anemia) is present in 25\% of anemic patients and anemia of chronic disease (normocytic normochromic) anemia is present in $60 \%$ of anemic patients and dimorphic anemia in 15\% anemic patients. Patients with anemia of chronic disease have higher disease activity (DAS 28 score) than iron deficiency anemia patients in rheumatoid arthritis. Rheumatoid factor, ESR, CRP and ferritin positively correlates with DAS 28 score significantly. Thrombocytosis is present in $31 \%$ of patients and eosinophilia is present in $27 \%$ of patients and very well correlated with DAS 28 score.

Conclusion: The clinical and hematological profile of the patients with rheumatoid arthritis is studied. In this study, attempt has been made to analyze the risk factors and outcome of anaemia on the severity of rheumatoid arthritis based on the DAS28 score.
\end{abstract}

\section{Introduction}

Rheumatoid Arthritis (RA) in this commonest form of chronic inflammatory joint disease. It is a symmetrical, non supportive polyarticular disease unique to modern man. ${ }^{1}$ Rheumatoid arthritis affects the synovial joints, but it is not confined to them and the many visceral manifestations have led to the classification of RA as a systemic disorder of the immunological mechanism. Of the systemic lesions, anemia and a focal subcutaneous granuloma are the most characteristic. Some cases of RA, particularly those that are seropositive, are fulminating and rapidly progress to severe deformity. ${ }^{1}$ Our aim is to study the hematological status in patients with rheumatoid arthritis and to find out the prevalence of anemia in these patients and its correlation with seropositivity and disease activity which is measured by DAS 28 score(Disease activity score).

\section{Materials And Methods}

It is a cross-sectional prospective study using convenient simple random sampling of 44 patients attending the rheumatology clinic in Coimbatore medical college hospital over a period of one year. Ethical committee clearance was obtained from the hospital.

\section{Inclusion criteria:}

1) Patients who satisfied the American Rheumatologic association criteria 1987, irrespective of hematological signs present or not

2) Age group 20 to 60 years irrespective of sex.

3) duration of disease upto 5 years.

\section{Exclusion criteria:}

1) Previously diagnosed anemia and treated

2) Previously have any other bleeding disorder not related to Rheumatoid arthritis. 
3) Those who have mixed disorder like SLE and RA ;SS\& RA and MCTD and overlap syndrome.

4) Previouslyknown malignancies, renal failure, hemolytic anemia any other chronic blood loss like hemorrhoids

Data analysis was done using epidemiological information statistical software. Using the software the frequencies, mean, standard deviation and $\mathrm{p}$ values calculated with yate's test for qualitative variables and kruskol walls chi square test for quantitative variables. $p$ value $<0.05$ is taken as significant.

\section{DAS 28 score}

Disease activity score is a composite score using tender and swollen joints count, ESR and patients global assessment activity using a $100 \mathrm{~mm}$ visual analogue scale.

\section{Classification}

Mild <3.1

Moderate 3.2-5.1

Severe $>5.1 \quad$ (Minimumscore: 0; Maximum score : 9 )

\section{Results}

In this study out of 44 cases, 35 were female and 9 were male. The age distribution is shown in Table-1.

Table 1: Age distribution

\begin{tabular}{|l|l|l|}
\hline \multirow{2}{*}{ Age group } & Cases & \% \\
\cline { 2 - 3 } & No. & 11.4 \\
\hline $20-29$ years & 5 & 27.3 \\
\hline $30-39$ years & 12 & 36.4 \\
\hline $40-49$ years & 16 & 25 \\
\hline $50-59$ years & 11 & 100 \\
\hline Total & 44 & \\
\hline Mean & 40.98 years & \\
S.D. & 9.73 years & \\
\hline
\end{tabular}

The table-2 shows that 2 people out of 44 (4.5\%) had mild disease and 23 people (52.3\%) has moderate disease. 20 people $(45.5 \%)$ had severe disease. DAS 28 score ranges from 2.75 to 5.81 with a mean value of 4.8 with standard deviation 0.78

Table 2: DAS Score 28

\begin{tabular}{|l|l|l|}
\hline DAS Score 28 & Cases \\
\hline Mild (<3.1) & 2 & 4.5 \\
\hline Moderate (3.2-5.1) & 23 & 52.3 \\
\hline Severe (>5.1) & 20 & 45.5 \\
\hline Total & 44 & 100 \\
\hline Score & & \\
Range & $2.75-5.81$ & \\
Mean & 4.8 & \\
S.D. & 0.78 & \\
\hline
\end{tabular}

Rheumatoid factor is positive in 35 cases (79.5\%) and negative in 9 cases $(20.5 \%)$. Serum proteins were normal. There was no reversal of albumin / globulin ratio and there was no hyperglobulinemia noticed in the study .Serum calcium and uric acid were normal in all patients. 27 patients showed radiological evidence of rheumatoid arthritis. No patients had splenomegaly or significant generalized lymphadenopathy. Concomitant usage of NSAIDS $80 \%$ and corticosteroids $40 \%$ and methotrexate $4 \%$ was present.

Among the 44 cases of rheumatoid arthritis 33 cases are anemic (75\%) and not anemic in 11 case $(25 \%)$ Mean hemoglobin level in patients was $10.67+1.83$

Table 3: Anemia and rheumatoid factor positivity:

\begin{tabular}{|l|l|}
\hline Anemic & $26 / 33$ \\
\hline Not anemic & $6 / 11$ \\
\hline$P$ value & 0.0305 significant \\
\hline
\end{tabular}

In patients who are anemic, number of rheumatoid factor positivity was $87 \%$ and in not anemic patients rheumatoid factor positivity was only $54 \%$. Mean $\mathrm{Hb}$ level in rheumatoid factor positivity was 9.11 gms +2.05 $\mathrm{SD}$. Mean $\mathrm{Hb}$ level in rheumatoid factor negativity was $10.23+1.19 \mathrm{SD}$. On analyzing the above values, anemia is one of the indicator of disease activity and severity of rheumatoid arthritis. 
Anemic and non-anemic patients were comparatively studied with their erythrocyte sedimentation rate levels and seropositivity for rheumatoid factor.Out of 33 patients 32 patients have elevated ESR out of which rheumatoid factor positive in 29 patients $(90.6 \%)$ whereas in 11 non anemic patients 10 had elevated ESR of which only 6 are rheumatoid factor positive $(60 \%)$. The values suggest that the anemic patients have more elevation of ESR and percentage of rheumatoid factor positivity is also more in this group.

Table 4:DAS 28 Score and duration of disease

\begin{tabular}{|l|l|l|}
\hline \multirow{2}{*}{ DAS 28 Score } & Duration of disease (in years) \\
\cline { 2 - 3 } & Mean & S.D. \\
\hline Mild & 2.0 & - \\
\hline Moderate & 2.83 & 1.17 \\
\hline Severe & 3.5 & 1.16 \\
\hline 'p' & $\begin{array}{l}\mathbf{0 . 0 4 7 1} \\
\text { Significant }\end{array}$ \\
\hline
\end{tabular}

When analyzing the above charts DAS 28 score was correlatedvery well with duration of disease.

Table5: Anemia and DAS 28 Score

\begin{tabular}{|l|l|l|}
\hline \multirow{2}{*}{ Anemia } & \multicolumn{2}{|l|}{ DAS 28 Score } \\
\cline { 2 - 3 } & Mean & S.D. \\
\hline Absent & 4.32 & 0.91 \\
\hline Present & 5.04 & 0.58 \\
\hline 'p' & $\begin{array}{l}\text { 0.0060 } \\
\text { Significant }\end{array}$ \\
\hline
\end{tabular}

When analyzing the data, incidence of anemia correlated with activity of disease and anemic patients had higher DAS 28 score than non-anemic patients. P value is significant.

Table 6: Peripheral smear study, Types of anemia and rheumatoid factor positivity

\begin{tabular}{|l|l|l|l|l|}
\hline & No.of pts & Percentage & Rheumatoid positivity & percentage \\
\hline Microcytic hypochromic & 8 & 18.2 & 8 & 100 \\
\hline Normocytic normochromic & 20 & 45.5 & 17 & 85 \\
\hline Dimorphic & 5 & 11.4 & 4 & 80 \\
\hline normal & 11 & 25 & 6 & 54 \\
\hline
\end{tabular}

When analyzing the above data 8 patients $(18.2 \%)$ patients show microcytic hypochromic anemia. Out of 8 patients all shows rheumatoid factor positivity. 20 patients $(45.5 \%)$ shows normocytic normochromic anemia.

Table 7:DAS 28 Score and Peripheral Smear Study

\begin{tabular}{|l|l|l|}
\hline \multirow{2}{*}{ Peripheral Smear Study } & DAS 28 Score \\
\cline { 2 - 3 } & Mean & S.D. \\
\hline Microcytic hypochromic anaemia & 4.77 & 0.35 \\
\hline Normocytic normochromic anaemia & 5.38 & 0.46 \\
\hline Dimorphic anemia & 4.71 & 0.48 \\
\hline Normal & 3.8 & 0.51 \\
\hline 'p' & $\begin{array}{l}\mathbf{0 . 0 0 0 1} \\
\text { Significant }\end{array}$ \\
\hline
\end{tabular}

When analyzing the above data, anemic patients have more DAS 28 score than non- anemic patients. Patients with normocytic anemia that means anemia of chronic disease has high DAS 28 score (5.38) than iron deficient patients (4.77) $\mathrm{p}$ value is significant 0.001 .

Table 8: Clinical and laboratory features of anemic and non-anemic patients:

\begin{tabular}{|c|c|c|c|c|c|}
\hline & \multicolumn{2}{|c|}{ Anemic patients } & \multicolumn{2}{|c|}{ Not anemic patients } & \\
\hline & Mean & S.D & Mean & S.D & P value \\
\hline Tender joint count, & 10.4 & 5.45 & 5.27 & 3.85 & 0.004 significant \\
\hline Swollen joint count & 6.5 & 3.78 & 3.28 & 4.82 & 0.006 significant \\
\hline Visual analogue scale & 66.10 & 53.1 & 31.2 & 43.3 & $\begin{array}{l}0.005 \\
\text { Significant }\end{array}$ \\
\hline Hemoglobin & 9.72 & 1.43 & 12.49 & 0.75 & $\begin{array}{l}\text { 0.0001 } \\
\text { significant }\end{array}$ \\
\hline Mean corpuscular volume & 78.27 & 8.87 & 86.42 & 5.3 & $\begin{array}{l}0.0036 \\
\text { significant }\end{array}$ \\
\hline Mean corpuscular hemoglobin & 24.51 & 3.63 & 27.92 & 2.2 & 0.0033 \\
\hline
\end{tabular}




\begin{tabular}{|l|l|l|l|l|l|}
\hline & & & & & significant \\
\hline $\begin{array}{l}\text { Mean corpuscular hemoglobin } \\
\text { concentration }\end{array}$ & 31.08 & 1.73 & 32.27 & 0.81 & $\begin{array}{l}\mathbf{0 . 0 0 7 1} \\
\text { Significant }\end{array}$ \\
\hline
\end{tabular}

In this study $\mathrm{MCV}, \mathrm{Hb}, \mathrm{MCH}$ and $\mathrm{MCHC}$ have higher values in anemic patients than non-anemic patients. p value was significant. In DAS 28 score we are using the variables like swollen joints, tender joints, visual analogue scale and ESR. ESR already shows the highly significant correlation with anemia and rheumatoid factor positivity and disease activity. Swollen joints and tender joints and visual analogue scale with anemia correlation were highly significant. $\mathrm{P}$ value was $<0.05$.

Out of 44 patients 13 patients have leukocytosis $(29.5 \%)$. No patient had leucopenia. Neutrophilia is present in 36 patients. Lymphopenia is present in $23 \%$ of patients. 12 patients (27\%) have eosinophils $>6 \%$. All 12 patients are rheumatoid factor positive. No patients had immature cells or large granular lymphocytes.Clotting time was normal in all patients. No patients had features of hyper viscosity syndrome and no patient had a features of Felty syndrome and no patient had a feature of pure red cell aplasia and no lymphoma and leukemia.

\section{Discussion}

In our study we selected 44 cases of rheumatoid arthritis on random basis as per the American rheumatism association guidelines 1987 . The sex distribution in this study, is predominantly affects females in a ratio of $4: 1$. Mean age is 58.5 years. In our study is 40.98 years. NavarocaroGregioet $a l^{(37)}$ andAbach, R.R. Buchanan et $\mathrm{al}^{(\mathbf{3 8})}$ in their study the severity of disease is in positive correlation with duration of disease. In this study patients who had disease more than 3 year have more DAS 28 score.

B.Fleeb, L.Andel, J.Sautner et $\mathrm{al}^{(39)}$, in their study the mean DAS 28 score was $4.23+1.2$.In this study mean DAS 28 score was $4.8+0.78$. In this study patients with mild DAS 28 was around $4.5 \%$ and moderate score was $52.3 \%$ and severe $45.5 \%$. This states that most of the patients are in moderate severity. Card Richard et al $^{(41)}$ in his study rheumatoid factor positivity was $80 \%$ and negativity $20 \%$. In this study RF positivity was $79.5 \%$ and while $20.5 \%$ RF was negative. The ratio of rheumatoid factor positivity to negativity is $4: 1$. Tracey Houston et al $^{(42)}$ in their study, mean hemoglobin in rheumatoid arthritis patients was $9.57 \mathrm{gm} \%$ and in this study mean $\mathrm{Hb}$ is $10.6 \mathrm{gm} \%$.

M. Kar, S. Roy et $a l^{(43)}$ in their study, mean hemoglobin level in rheumatoid positivity patients was $9.57 \mathrm{gm} \%$ and $10.45 \mathrm{gm} \%$. Among rheumatoid negative patients. In this study mean $\mathrm{Hb}$ level in rheumatoid factor positive patients is $9.11+2.05$ and mean $\mathrm{Hb}$ among rheumatoid factor negative is $10.23+1.19 \mathrm{gm} \%$. This states that anemia is very well correlated with rheumatoid factor positivity and disease activity.

Agarwal Sumeetet $a l^{(45)}$ in their study, mean DAS 28 score in non-anemic patients was 3.83 compared to anemic patients which was 5.13. In this study in non-anemic patients mean DAS 28 score is 4.32 and in anemic patients 5.04. D J Borah ,Farhis Iqbal et $a l^{(44)}$ in their study, in non-anemic patients mean DAS 28 score was 4.76 while anemic patients it was 6.85 .This states that anemic patients have more DAS score and disease activity than non anemic patients.

Agarwal Sumeet et al ${ }^{(45)}$, in their study, of rheumatoid arthritis patients with iron deficiency anemia DAS 28 score was 4.7 and in patients with anemia of chronic disease DAS 28 score was 5.69. In this study patients with iron deficiency DAS 28 score was 4.77 and in anemia of chronic disease was 5.38. The p value is significant $(0.001)$. This states that DAS 28 score is higher in ACD than in IDA.

In this study iron deficiency anemia patients are less $(24.5 \%)$ because iron deficient anemia with inflammation(Dimorphic anemia )is included separately(15\%) and there is a probable folic acid and/or Vit B12 deficiency. Microcytosis (<80 femtolitre) in this study is $27 \%$ patients among rheumatoid arthritis patients .Alexander et $a l^{(8)}$ in their study showed $30 \%$ prevalence of microcytosis.

Hypochromia (less than 26pg) is present in $38 \%$ of rheumatoid arthritis patients in this study. Caris J Bastley et al ${ }^{(55)}$ reported $50 \%$ hypochromia in their study.

Sumeet Agarwal et $a l^{(45)}$ and D J Borah, Fahler Iqbalet $a l^{(44)}$ in their study, the variables used in calculating DAS 28 score like tender joint count, swollen joint count, ESR and visual analogue scale was correlated significantly. The $\mathrm{p}$ value was more significant in anemic patients than non anemic patients .In this study also all the 4 variables shows high significance in anemic patients compared to non anemic patients. Agarwal et $a l^{(\mathbf{4 5})}$ in their study; tender joint count, swollen joint count, ESR and visual analogue scale in patients with anemia of chronic disease showed higher value than iron deficiency anemic patients. Similar results were obtained in all the variables showing higher significance in patients with anemia of chronic disease than iron deficiency anemic patients in this study. The $\mathrm{p}$ value is significant.

Hutchusonet $a l^{(57)}$ and Dulaguistet $a l^{(58)}$ in their study thrombocytosis in rheumatoid arthritis was $52 \%$ and $60 \%$ respectively AlofSelross et al ${ }^{(59)}$ in their study ;thrombocytosis was present in $33 \%$ of patients and it correlated with disease activity. In our study thrombocytosis is present in $31 \%$. Patients with thombocytosis have higher DAS 28 score with significant $\mathrm{p}$ value. 
Agarwal Sachdevet $a l^{(63)}$ reported pure red cell aplasia and immune thrombocytopenia. In this study no patients had thrombocytopenia and pure red cell aplasia. No patient had decreased red cell distribution width. Abach,R,R,Buchnanet $a l^{\mathbf{3 8})}$ reported a hyperviscosity syndrome in rheumatoid arthritis. In this study no patient had symptoms suggestive of hyperviscosity syndrome.

Paraiaz ,Fayazetal ${ }^{(33)}$ study none of the patient of rheumatoid arthritis had evidence of bleeding and DIC. An only isolated abnormality of coagulation was present. Protein C and protein S was low in 1 case each while decreased factor VIII level was detected in 5 cases. Hypofibrinogenemia was demonstrated in 1 case. All patients had normal factor IX level. In this study no patient had evidence of bleeding and abnormal bleeding time as well as clotting time.

\section{Conclusion}

Sex ratio of females to males is this study is $4: 1$. The risk of developing disease is greatest between 40 to 49 years. Rheumatoid factor positivity is $80 \%$ and rheumatoid factor negativity is $20 \%$. The prevalence of anemia inrheumatoid arthritis patients is $75 \%$. In rheumatoid factor positive patients mean $\mathrm{Hb}$ values is less $(9.11 \mathrm{gm} \%)$ compared to rheumatoid factor negative patients $(10.23 \mathrm{gm} \%)$. Iron deficiency anemia patients mean $\mathrm{Hb}$ islower(8.6gm\%) than in anemia of chronic disease is $(10.9 \mathrm{gm} \%)$. The prevalence of rheumatoid arthritis according to DAS 28 scorecategories in decreasing order are moderate $52.3 \%$, severe $45.5 \%$ and mild $4.5 \%$.Anemia is very well correlated with rheumatoid factor positivity, disease activity (DAS 28 score), duration of disease and ESR.

Microcytic hypochromic anemia (iron deficiency anemia) is present in $25 \%$ of anemic patients and anemia of chronic disease (normocytic normochromic) anemia is present in $60 \%$ of anemicpatients and dimorphic anemia in $15 \%$ anemic patients.Patients with anemia of chronic disease have higher disease activity (DAS 28 score) than iron deficiency anemia patients in rheumatoid arthritis.Rheumatoid factor, ESR, CRP and ferritin positively correlates with DAS 28 score significantly. Thrombocytosis is present in $31 \%$ of patients and eosinophilia is present in $27 \%$ of patients and very well correlated with DAS 28 score. $29.5 \%$ have leukocytosis, while none of the patients have leucopenia. Lymphopenia is present in $20 \%$ of RA patients. Bleeding time and clotting time are normal among all patients .

\section{References}

[1]. Anemia in rheumatoid arthritis - scandinavian journal of rheumatology 1966 54:1

[2]. Richmond J, Alexander et al :nature of anemia in rheumatoid arthritis Annals of Rheumatic disease 20:133-137, 1961.

[3]. Wintrobes text book of clinical hematology

[4]. Cart wright,.G.E.; anemia of chronic disorders semin. hematology 3:351-375,1976

[5]. Lewis S.M.Porteretal, erythrocyte survival in rheumatoid arthritis; American rheumatic disease 19:54-58, 1960

[6]. Baer an,dressypis, blunted erythropoietic response in anemia in rheumatoid arthritis-British Journal of hematology 1987,66;579614

[7]. Cavil.I, Bentley D.P, erythropoietin in anemia of rheumatoid arthritis; British journal of hematology 50,1982 583-590

[8]. DinanatH.J.DEmat C.E.M- erythropoiesis and mean red cell life span in normal subjects and in patients with rheumatoid arthritis British Journal of hematology39; 437-444.

[9]. Douglas; S.W. Adamson . J. et al, anemia of chronic disorders: studies of marrow regulation and iron metabolism Blood 45:55-565, 1975

[10]. Mahmood, T.Robinsonw,a, Vautrin .R, granulopoeitic and erythropoeiteic activity in anemia of iron deficiency and chronic disease;; Blood 50:449-455,1977

[11]. Ward H.P., Gordon B, Pickett, J.c serum levels of erythropoietin in rheumatoid arthritis;; Journal of lab clini.med 74;93-97, 1969

[12]. Boyd.H,K, LappinT.R.Bell - evidence for impaired erythropoietic response to anemia in rheumatoid disease . Department of hematology Royalvictoria hospital British Journal of rheumatology 1991 aug 30 (4) 255-259

[13]. Roodman G.D. mechanism of erythroid suppression in anemia of chronic disease Blood cells 1987

[14]. Maury CPJ, Anderson Lc, Teppoem et al , mechanism of anemia in rheumatoid arthritis .Ann. rheumatic disease 1988 972-978

[15]. Lee.G.R. anemia of chronic disease Semin.Hemat. 20:61-80, 1983

[16]. Casali. B;Salvo.D: the role of IL 1, erythropoietin and red cell bound Ig in anemia of rheumatoid arthritis.Clini. Exp. rheumat. 1991 may-June 9(3)241-246 